\title{
Neutrophil oxidative metabolism and killing of $P$. brasiliensis after air pouch infection of susceptible and resistant mice
}

\author{
Lucia Helena Meloni-Bruneri," Ana Campa, ${ }^{\star}$ Dulcineia S. P. Abdalla, " Vera Lucia Garcia \\ Calich, ${ }^{\dagger}$ Henrique L. Lenzi, ${ }^{\mp}$ and Eva Burger ${ }^{\dagger}$ \\ *Departamento de Análises Clínicas e Toxicológicas, Faculdade de Ciências Farmacêuticas, and ${ }^{\dagger}$ Departamento de \\ Imunologia, Instituto de Ciências Biomédicas, Universidade de São Paulo; and ${ }^{\ddagger}$ Departamento de Patologia, \\ Fundação Oswaldo Cruz, Rio de Janeiro, Brasil
}

\begin{abstract}
The oxidative burst of polymorphonuclear neutrophils (PMN) and their ability to inhibit Paracoccidioides brasiliensis growth was studied in susceptible (B10.A) and resistant (A/J) mice. The cells were obtained after subcutaneous inoculation in air pouches, yielding highly pure PMN preparations; the number of cells was similar for both strains at 24 $h$ and five times higher in the resistant strain at 15 days. The oxidative metabolism of these PMN was evaluated by the luminol and lucigen-enhanced chemiluminescence upon stimulation with PMA or killed $P$. brasiliensis (Pb). At 24 h of infection PMN from both strains showed similar responses. However, at 15 days a great enhancement of the $\mathbf{P b}$ stimulated luminol-enhanced chemiluminescence was observed only in PMN from resistant mice. Such increase was markedly inhibited by the addition of catalase. Independent of the mouse strain or time of infection the lucigenin-enhanced chemiluminescence showed the same intensity. The lucigenin-enhanced chemiluminescence of PMN without stimuli from resistant mice did not change with the time of infection, however, after 15 days of infection a significantly lower chemiluminescence was detected with PMN from susceptible mice. At 15 days of infection the PMN from B10.A were unable to kill $P$. brasiliensis yeast cells in vitro. Because the lucigenin- and luminol-enhanced chemiluminescence detects, respectively, the $\mathrm{O}_{2}^{-}$production and the myeloperoxidase/hydrogen peroxide halide system, the present data show parallels between deficiency in the production of oxygen-reactive species by PMN and lower fungicidal activity. J. Leukoc. Biol. 59: 526-533; 1996.
\end{abstract}

Key Words: polymorphonuclear neutrophils - myeloperoxidase · luminol $\cdot$ lucigenin $\cdot$ chemiluminescence

\section{INTRODUCTION}

Paracoccidioides brasiliensis is a dimorphic fungus that causes a deep human granulomatous mycosis, endemic in Latin America and frequently diagnosed in Brasil [1].
Studies using isogenic mice in experimental paracoccidioidomycosis were developed for the first time by Calich et al. in 1985, who demonstrated the existence of susceptible (B10.A) and resistant $(\mathrm{A} / \mathrm{Sn}, \mathrm{A} / \mathrm{J})$ mice, after intraperitoneal (i.p.) infection with a virulent $P$. brasiliensis (Pb18) isolate [2]. Although a polar behavior could be observed after i.p. infection of $\mathrm{A} / \mathrm{J}$ and B10.A strains, the same was not true when the subcutaneous (s.c.) route was used; this route was unable to induce systemic disease and caused only a localized inflammatory process that progressed to cure in both $\mathrm{A} / \mathrm{Sn}$ and B10.A strains [2]. An acute inflammatory infiltrate in which polymorphonuclear neutrophil (PMN) cells predominated was observed by using the s.c. and i.p. routes of infection in Swiss [3] and B10.A [4] mice, respectively. The PMN influx was previously shown to be independent of the activation of the complement system as well as of the effects of other chemotactic substances, such as prostaglandin. However, it was induced by a low-molecular-weight peptide produced by macrophages incubated with $P$. brasiliensis yeasts [4].

The role of PMN in paracoccidioidomycosis is not well established yet, as reviewed by Brummer et al. [5]. In this regard, PMN from blood of patients with paracoccidioidomycosis [6] or from peritoneal exudate of sensitized mice [7] could kill $P$. brasiliensis in vitro and inflammatory PMN had more pronounced fungicidal activity than peripheral blood PMN [7-9]. Goihman-Yahr et al. [10] showed that PMN from patients with paracoccidioidomycosis had normal phagocytic activity but had a defect in their in vitro digestive capability against phagocytosed $P$. brasiliensis yeasts when compared with PMN from healthy subjects or patients with other diseases. However, Schaffner et al. [11] have shown that PMN isolated from blood of healthy individuals ingested virulent dimorphic yeasts, triggering the

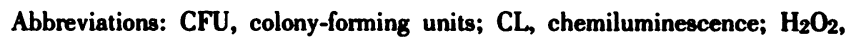
hydrogen peroxide; MPO, myeloperoxidase; $\mathrm{O}_{2}{ }_{2}$, superoxide anion; $\mathrm{Pb}$, heat-killed Paracoccidioides brasiliensis; PMA, phorbol myristate acetate; PMN, polymorphonuclear neutrophils; ROS, reactive oxygen species; PBS, phosphate-buffered saline; DMEM, Dulbecco's modified Eagle's medium.

Reprint requests: Lucia H. Meloni-Bruneri, Departamento de Análises Clínicas e Toxicológicas, Faculdade de Ciências Farmacêuticas, Universidade de São Paulo, Av. Lineu Prestes 580, 05508-900 São Paulo, SP, Brasil.

Received February 1, 1995; revised September 15, 1995; accepted December $11,1995$.
} 
respiratory burst, but were not able to kill the virulent $P$. brasiliensis yeast cells.

Substantial amounts of reactive oxygen species (ROS) are produced during phagocytosis or upon perturbation of PMN membranes by a variety of agents, such as phorbol myristate acetate (PMA) or stimuli by particulate agents. Species such as superoxide anion $\left(\mathrm{O}_{2}^{-}\right)$, hydrogen peroxide $\left(\mathrm{H}_{2} \mathrm{O}_{2}\right)$, hydroxyl radicals ( $\left.\mathrm{HO} \cdot\right)$, hypochloride ion $(\mathrm{OCl}-)$, hypochloride acid $(\mathrm{HOCl})$, and chloroamines are released from PMN through the NADPH oxidase and hydrogen peroxide-myeloperoxidase-halide systems $\left(\mathrm{H}_{2} \mathrm{O}_{2}\right.$-MPO-halide). These species released by PMN or by a cell-free system were shown to be fungicidal for dimorphic fungi such as $P$. brasiliensis [7, 12-16], and for opportunistic fungi [11, 17-19].

This activation, caused by a variety of stimuli to trigger PMN ROS production, can be determined by measuring chemiluminescence (CL) in the presence of the luminescent probes luminol and lucigenin. Products of the $\mathrm{H}_{2} \mathrm{O}_{2}$ MPO-halide system can be measured by luminol-enhanced CL $[20,21]$ while superoxide anion can be detected by lucigenin-enhanced CL $[21,22]$.

In the isogenic murine model of paracoccidioidomycosis, it was shown that the macrophages of resistant mice are

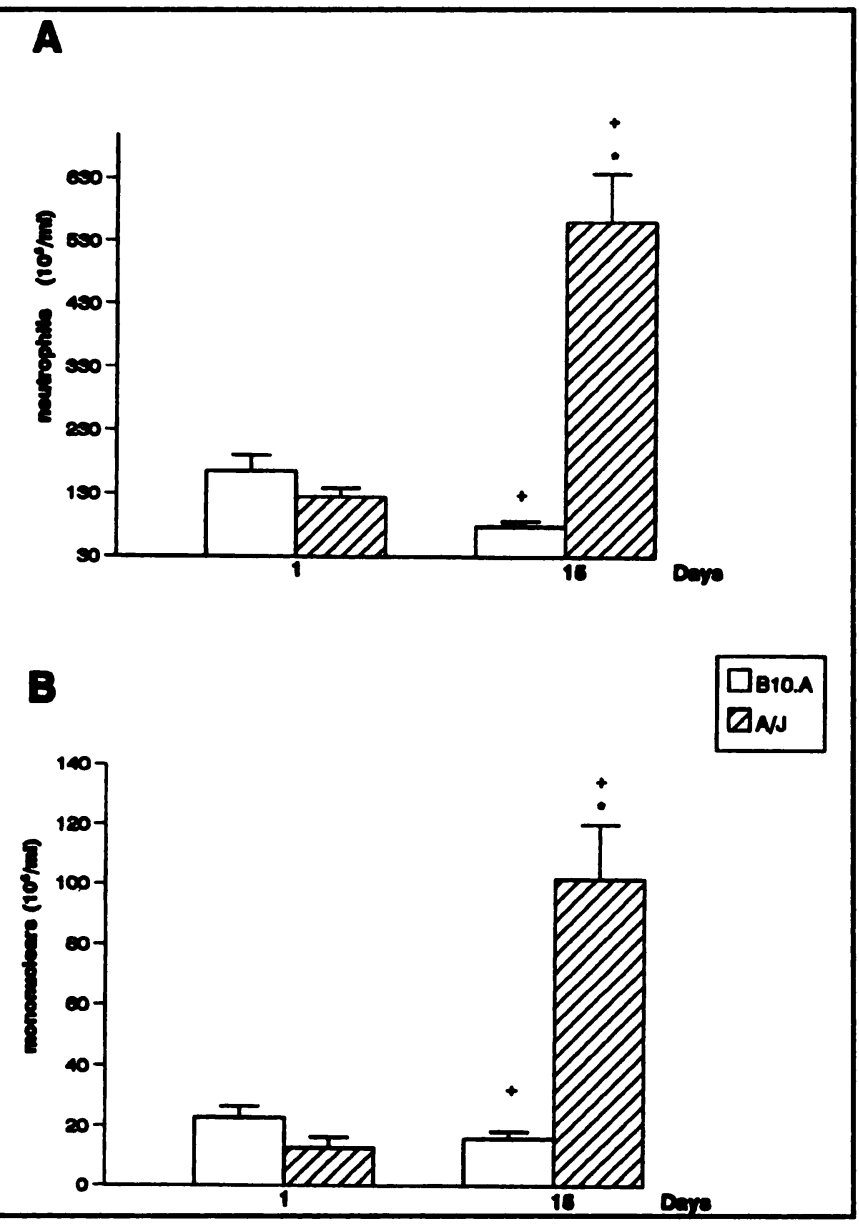

Fig. 1. Absolute counts of PMN (A) and mononuclear cells (B) from air pouches of $\mathrm{A} / \mathrm{J}$ and $\mathrm{B} 10 . \mathrm{A}$ mice, $24 \mathrm{~h}$ and 15 days after infection with $P$. brasiliensis. *Statistical difference between mouse strains (A/J and B10.A). more activated than those of susceptible ones by various parameters, such as $\mathrm{H}_{2} \mathrm{O}_{2}$ production, spreading ability, and expression of class II molecules [2]. In the present work we intended to verify whether similar differences in activation also occur in PMN of susceptible and resistant mice. Therefore we investigated the changes in the ROS production by the NADPH oxidase- and MPO-dependent systems in PMN obtained from air pouches of $A / J$ and B10.A mice infected with a virulent $P$. brasiliensis isolate.

Previous works have demonstrated that PMN are associated with degenerated $P$. brasiliensis yeast cells in the lesions of animals in which the infection evolves to cure [23]. Therefore, in the present study, the PMN were also analyzed regarding their fungal killing ability, attempting to determine whether a correlation between higher activation and a more pronounced killing ability of PMN occurs in this experimental model.

\section{MATERIALS AND METHODS}

\section{Animals}

Male A/J and B10.A, 10- to 12-week-old mice, obtained from the Departamento de Imunologia, Instituto de Ciências Biomédicas, Universidade de São Paulo, animal facilities were used throughout this work. The mice were fed with laboratory chow (Nuvilab CR-1, Nuvital) and acidified water ad libitum, and kept in a temperature-controlled room $\left(22^{\circ} \mathrm{C}\right)$, housed in groups of 8-10.

\section{Fungi}

The virulent $\mathrm{Pb} 18 \boldsymbol{P}$. brasiliensis isolate was maintained in potato-agar and covered with mineral oil until being employed in the experimental studies to avoid excessive subcultivation. Virulence of $\mathrm{Pbl} 18$ was controlled by LD50\% determinations and at any evidence of virulence loss the sample was re-isolated from susceptible mice according to Kashino et al. [24]. P. brasiliensis in its yeast form was cultivated in semi-solid Fava Netto's medium at $35^{\circ} \mathrm{C}$ [25] and employed on the 7th day of culture, which corresponds to the exponential phase of growth [26].

\section{$P$. brasiliensis inoculation}

The yeast cells were washed three times in sterile saline and the fungal suspensions were adjusted, after counting in a hemacytometer, to the desired concentration with phosphate-buffered saline (PBS). The viability of the fungal cells was evaluated using the vital dye Janus Creen B (Merck) [27] and was always $>85 \%$.

Air pouches were produced on the dorsal region of mice by s.c. injection of $2 \mathrm{ml}$ of air, employing the technique of Harmsen et al. with some modifications [28]. Fungal suspensions of $50 \times 10^{6}$ yeasts $/ \mathrm{ml}$ in $100 \mu \mathrm{l}$ of PBS or $100 \mu \mathrm{l}$ of PBS alone were injected in the experimental groups and in the controls, respectively.

\section{Collection of PMN}

PMN were collected after $24 \mathrm{~h}$ and after 15 days of fungal infection. For each experiment, mice were anesthetized with ethyl ether and inoculated in the air pouches with a solution of PBS (10 mM; Merck), $\mathrm{pH} 7.4$, containing $10 \mu \mathrm{l} \mathrm{CaCl}$ (lmM; Merck), $10 \mu \mathrm{l} \mathrm{MgCl} 2$ (0.5 mM; Merck), and $10 \mu \mathrm{l}$ glucose $(1 \mathrm{mg} / \mathrm{ml}$; Merck). After incision of the skin, cells were collected with a siliconized Pasteur pipette and counted in Neubauer chambers. Each air pouch yielded $\sim 1 \mathrm{ml}$ of exudate. Viability was estimated by Trypan blue exclusion and was $86 \%$ at $24 \mathrm{~h}$ after infection for PMN of either strain. At 15 days of infection, the viability 


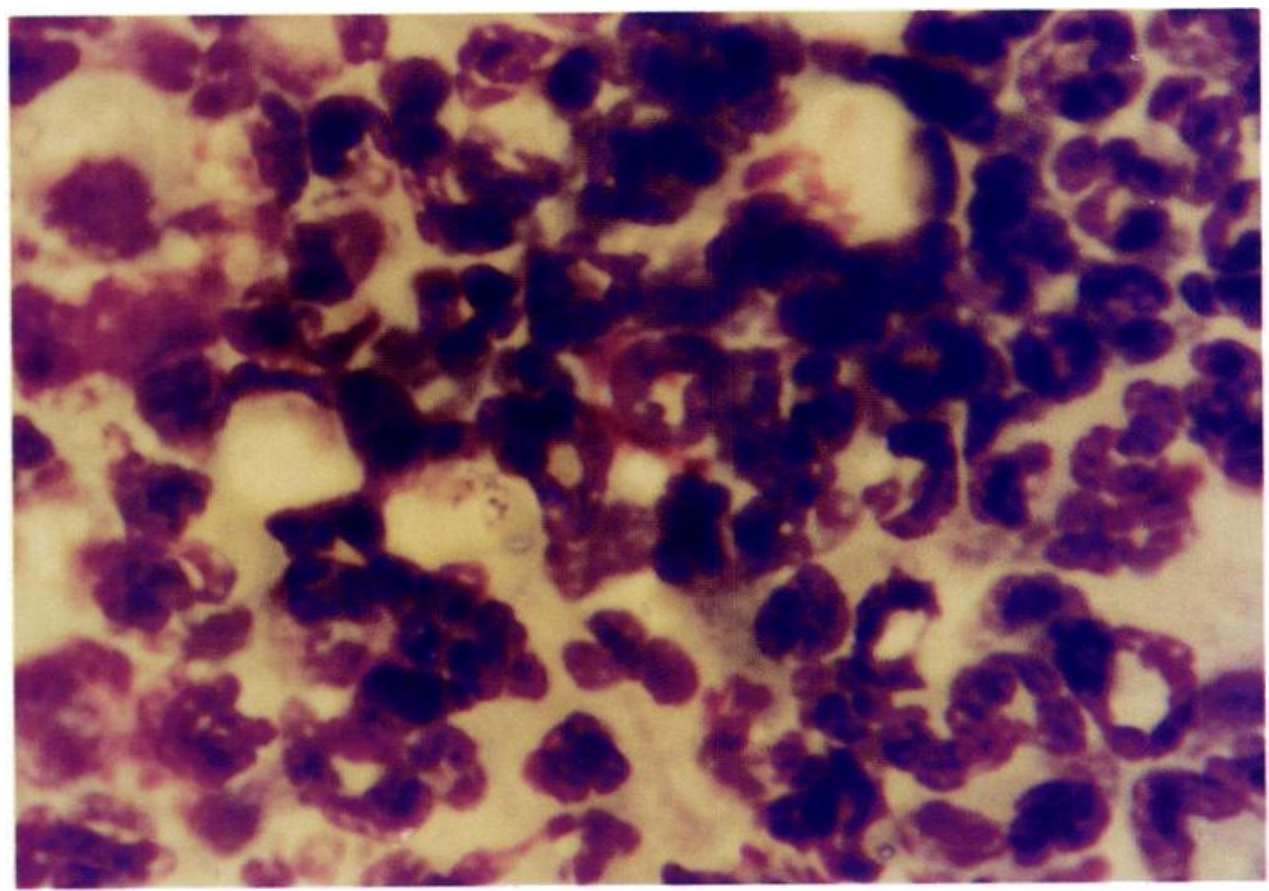

Fig. 2. Typical aspect of air pouch exudate with $81-90 \%$ of PMN cells from B10.A mice 15 days after infection with $P$. brasiliensis stained with May-Grunwald-Giemsa $(X$ 1000).

observed for PMN from A/J mice was $50 \%$ and for PMN from B10.A was $60 \%$. The same numbers of viable PMN were always used for both strains. Cytological analyses were done in cell preparations obtained with Suta chambers and were stained with May Grunwald-Giemsa (Merck). For each assay, four to eight pools (3 animals/pool) were used.

\section{Histopathological analysis}

At 15 days after the inoculation of $P$. brasiliensis in the s.c. air pouch the mice were killed and the whole air pouch, with the formed lesion, was collected and fixed in Millonig [29], at $\mathrm{pH}$ 7.0-7.4. The samples were embedded in parafin and the slides stained with hematoxylin/eosin.

\section{Chemiluminescence assays}

The modified luminol-enhanced CL method of Allen and Loose [20] was used to detect the products of the oxidative metabolism dependent on the $\mathrm{H}_{2} \mathrm{O}_{2}$-MPO-halide system. The products of the NADPH oxidase system, primarily $\mathrm{O}_{2}{ }^{-}$, were measured by the lucigenin-enhanced CL method of Mikenberg et al. [22]. In vitro stimulation was performed either with PMA or with heat-killed $P$. brasiliensis yeast cells $(\mathrm{Pb})$ by steam autoclaving at $100^{\circ} \mathrm{C}$, at $120 \mathrm{~atm}$, for $20 \mathrm{~min}$.

The reaction contained viable $1 \times 10^{6} \mathrm{PMN}, 10 \mu \mathrm{l}$ PMA $(50 \mathrm{ng} / \mathrm{ml}$; Sigma) or $1 \times 10^{6}$ killed $\mathrm{Pb}$ yeasts, $10 \mu \mathrm{l}$ luminol ( $1 \mathrm{mM}$; Sigma) or 50 $\mu l$ lucigenin (25 mM; Sigma) in $2 \mathrm{ml}$ PBS. In some experiments, $200 \mu \mathrm{l}$ of catalase ( $3 \mathrm{mg} / \mathrm{ml}$; Sigma) was added to the reaction with luminol to consume $\mathrm{H}_{2} \mathrm{O}_{2}$. The experiments were done at room temperature $\left(20-22^{\circ} \mathrm{C}\right)$ and photon emission was detected in a scintillation counter (model 1900TR-Packard, Camberra Co.). The kinetics studies were started without in vitro stimulus or by addition of stimulus, and light emission (counts per minute) was recorded during 40-60 min. Controls of $\mathrm{CL}$ by dead $\mathrm{PMN}$ and $\mathrm{Pb}$ showed negligible values.

\section{P. brasiliensis killing assay by air pouch PMN}

A pool of 10 mice of each strain was used to obtain PMN from air pouches after 15 days of infection and the killing assay was performed according to Mc Ewen et al. [7] with some modifications. P. brasiliensis yeast suspensions were obtained as previously described, the concentration adjusted to $1 \times 10^{5}$ yeasts $/ \mathrm{ml}$ in Dulbecco's modified Eagle's medium (DMEM) suplemented with 30\% fresh normal mouse serum. Opsonization with fresh mouse normal serum was performed during $\mathbf{2 0}$ min at $37^{\circ} \mathrm{C}$. Mice were killed for PMN collection and the cells from the air pouch lesions were incubated in DMEM (Sigma) with $10 \%$ fetal calf serum (Cultilab). Elimination of adherent cells, mostly mononuclear cells, was performed by incubation of cell suspensions in plastic Petri dishes for $30 \mathrm{~min}$ at $35^{\circ} \mathrm{C}$ in a $5 \% \mathrm{CO}_{2}$ atmosphere. The nonadherent cells, constituted by $95 \%$ of PMN, were collected, washed with DMEM, and adjusted to a final concentration of $5 \times 10^{6}$ viable PMN $/ \mathrm{ml}$. Cocultures were done in a ratio of 50 PMN: $1 P$. brasiliensis yeast. The PMN suspensions $(100 \mu \mathrm{l})$ and $100 \mu \mathrm{l}$ of $10^{4}$ fungi were dispensed in quadruplicate into microplate wells (Costar). Controls consisted of PMN recovered from air pouch-infected mice without in vitro addition of $\boldsymbol{P}$.
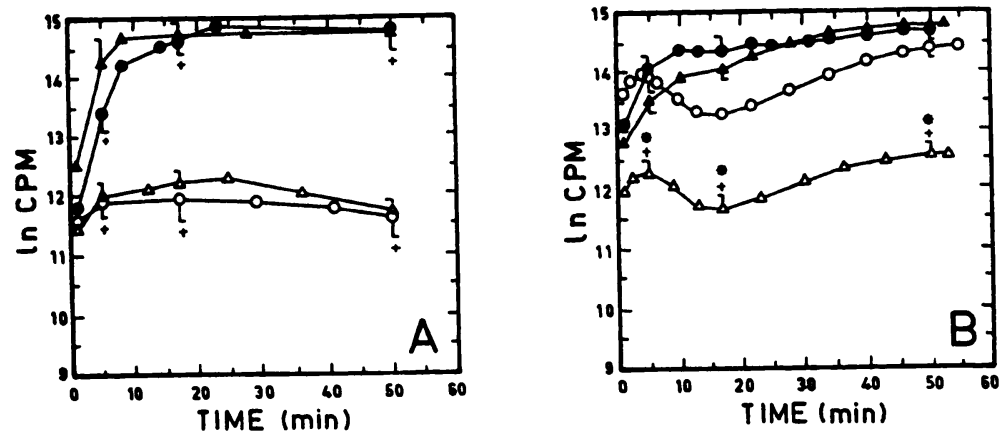

Fig. 3. Luminol-enhanced chemiluminescence of $P M N$ from B10.A $(\Delta, \Delta)$ and $A / J(O, O)$ obtained $24 \mathrm{~h}(\mathrm{~A})$ and 15 days $(B)$ after air pouch infection with $\mathrm{Pb} 18 P$. brasiliensis. PMN $\left(5 \times 10^{5} / \mathrm{ml}\right)$ were stimulated in vitro by PMA (filled symbols) or by $\mathrm{Pb}\left(5 \times 10^{5} / \mathrm{ml}\right.$; open symbols). ${ }^{+}$Statistical difference between stimuli (PMA and $\mathrm{Pb}) ;{ }^{*}$ statistical difference between mouse strains (A/J and B10.A). 
brasiliensis yeasts or of $100 \mu \mathrm{l}$ of $10^{4}$ fungi cultured only in medium $(\mathrm{DMEM}+\mathrm{Pb})$. After incubation for $2 \mathrm{~h}$ at $37^{\circ} \mathrm{C}$, in $5 \% \mathrm{CO}_{2}$, the cells were collected, the wells washed three times with $100 \mu \mathrm{l}$ of distilled water, and the volume of each sample was completed to $5 \mathrm{ml}$ with distilled water for PMN lysis and release of ingested $P$. brasiliensis yeasts.

Volumes of $100 \mu \mathrm{l}$ of each sample were seeded in duplicate in plates containing brain heart infusion medium supplemented with $4 \%(\mathrm{v} / \mathrm{v})$ horse serum and 5\% P. brasiliensis isolate $\mathrm{Pbl} 192$ culture filtrate, the latter constituting a source of growth-promoting factor [30, 31]. The plates were sealed, incubated at $37^{\circ} \mathrm{C}$, and colonies were counted daily for 15 days. The results were expressed as average means and standard errors of the means of the colony forming units (CFU) counted.

\section{Statistics}

Means and standard errors of means (SE) of light emission data were transformed in neperian logarithms while means and SE of CFU counts, PMN, and mononuclear absolute counts were transformed in square root and analyzed by the Kruskal-Wallis variance tests. CL comparisons were done at 5,17 , and 30 or $50 \mathrm{~min}$. The significance level considered was $P<0.05$. Multiple comparisons were done according to Tukey [32]. For all statistical tests, the Statgraphics, V.2.6 (1987), software was used.

\section{RESULTS}

\section{Cytological analysis}

The air pouches of $\mathrm{A} / \mathrm{J}$ and B10.A strains of mice had $1.2-1.6 \times 10^{7}$ neutrophils $/ \mathrm{ml}$ at $24 \mathrm{~h}$ after $P$. brasiliensis infection. At 15 days of infection, the number of neutrophils observed in $\mathrm{A} / \mathrm{J}$ mice increased five times, whereas B10.A showed a $50 \%$ decrease compared with $24 \mathrm{~h}$ infection (Fig. 1A). In differential counts, 81-90\% of the cells were PMN and the remaining were mononuclear cells, in- dependent of time of infection. At $24 \mathrm{~h}$ of infection, the absolute counts of mononuclear cells were the same (Fig. 1B). At 15 days of infection, however, the absolute number of mononuclear cells was approximately five times higher in the A/J strain than in the B10.A (Fig. 1B). Figure 2 shows a typical aspect of the exudate obtained 15 days after B10.A infection, which did not differ from that obtained with $\mathrm{A} / \mathrm{J}$ mice. In control animals $10^{4}$ neutro$\mathrm{phils} / \mathrm{ml}$ were found at both analyzed periods.

\section{Histopathological analysis}

Optical microscopy observation revealed different patterns of cellular influx in the two mouse strains. The resistant A/J strain developed a typical abscess, constituted mostly by PMN and present in the lesion of typical mononuclear cells. On the other hand, the susceptible B10.A mice developed smaller lesions, with numerous PMN aggregates surrounded by mononuclear cells such as macrophages and epithelioid cells (data not shown).

\section{Luminol-enhanced CL}

Figure 3 shows the luminol-enhanced CL developed by neutrophils from $\mathrm{A} / \mathrm{J}$ and B10.A mice, obtained after $24 \mathrm{~h}$ and 15 days of infection using $\mathrm{PMA}$ or $\mathrm{Pb}$ as stimulus. With PMA the kinetics and intensities of $C L$ were equivalent, independent of the mouse strain or of the time of. infection. The intensities of CL, as well the kinetics obtained, were dependent on the stimulus employed. PMA stimulation elicited $\sim 16$ times more $\mathrm{CL}$ than $\mathrm{Pb}$ with $\mathrm{PMN}$ obtained after $24 \mathrm{~h}$ of infection (Fig. 3A). Pb stimulation showed a biphasic kinetics typical of particulate stimulus in both strains only at 15 days of infection (Fig. 3B). At
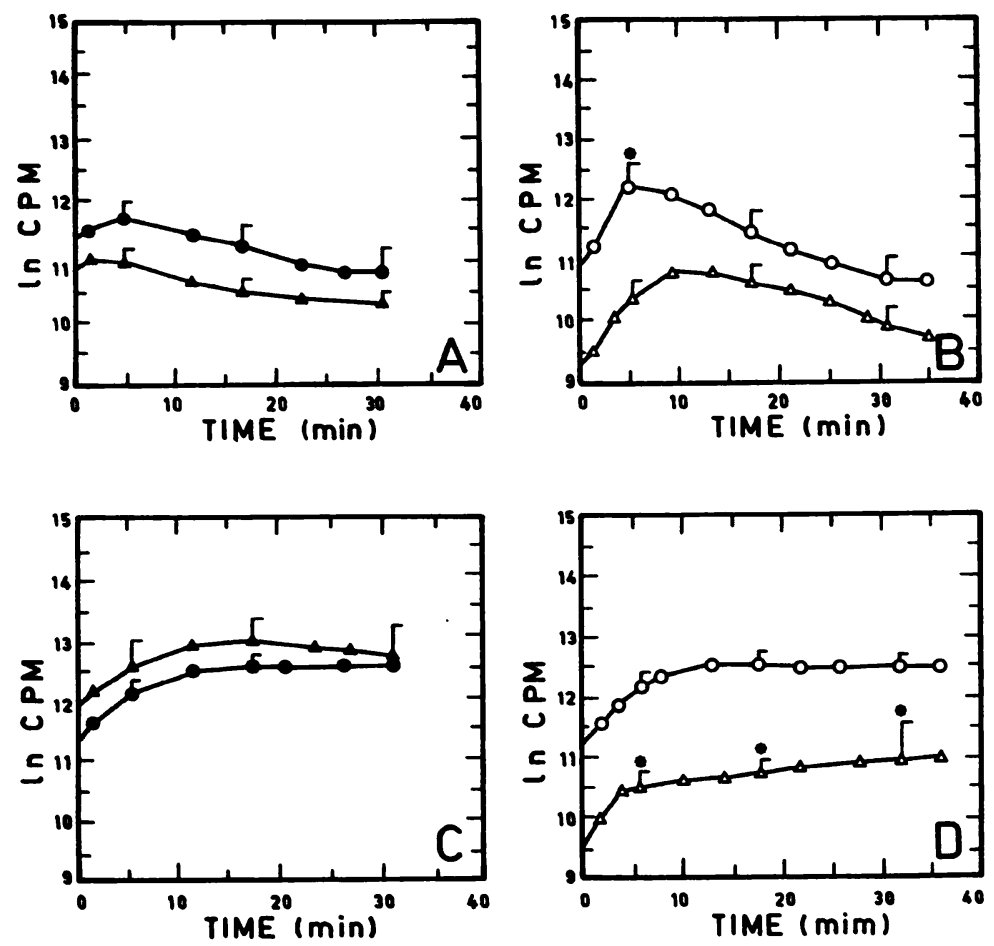

Fig. 4. Luminol (A, B)- and lucigenin (C, D)-enhanced chemiluminescence, without in vitro stimuli, of PMN from B10.A $(\Delta, \Delta)$ and $A / J(O, O)$ obtained $24 h$ (filled symbols) or 15 days (open symbols) after air pouch infection with $\mathrm{Pbl8} P$. brasiliensis. ${ }^{+}$Statistical difference between time of infection ( $24 \mathrm{~h}$ and 15 days); *statistical differences between mouse strains ( $\mathrm{A} / \mathrm{J}$ and B10.A). 

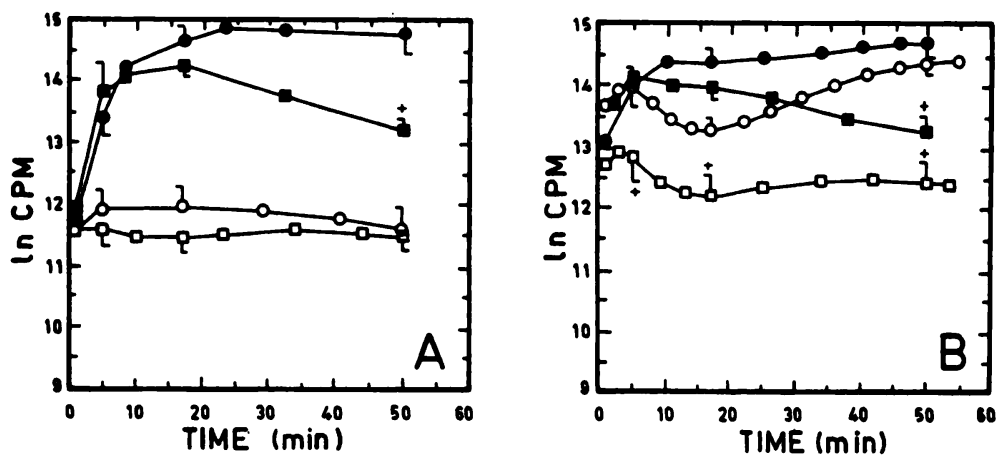

Fig. 5. Effect of catalase in the luminol-enhanced chemiluminescence of PMN from A/J stimulated by PMA (filled symbols) or by $\mathrm{Pb}$ (open symbols) $24 \mathrm{~h}$ (A) or 15 days (B) after air pouch infection with $\mathrm{Pb} 18 \mathrm{P}$. brasiliensis. Without catalase $(O, O)$, with catalase $(\square, \square) ;{ }^{+}$statistical difference between treatments.

this time of infection, a sharp difference of $\mathrm{Pb}$-induced $\mathrm{CL}$ was seen between $\mathrm{A} / \mathrm{J}$ and B10.A cells. The luminol-enhanced CL of PMN from $A / J$ was five times higher than that of B10.A and seven times more than that of PMN collected from $\mathrm{A} / \mathrm{J}$ at $24 \mathrm{~h}$ after infection. In contrast, no differences in $\mathrm{CL}$ intensities were observed for PMN from B10.A animals at any post-infection time (Fig. 3, A and B).

CL was also followed without in vitro addition of stimulus (Fig. 4). In this case, the CL intensity was lower than that obtained when PMA or $\mathrm{Pb}$ were added. No differences were observed after $24 \mathrm{~h}$ of infection for both mouse strains (Fig. 4A). However, after 15 days of infection, the luminolenhanced $C L$ of cells from $A / J$ mice was approximately five times higher than that of cells from Bl0.A at $5 \mathrm{~min}$ of reaction (Fig. 4B).

Differences between animal strains and time of infection regarding the $\mathrm{H}_{2} \mathrm{O}_{2}$-MPO-halide system could also be observed in the experiments in which catalase was added (Figs. 5 and 6). Catalase inhibited the intensity of luminol CL of PMA-stimulated PMN from both strains at both times of infection. The catalase effect was time dependent, with an inhibition of $60-80 \%$ at $50 \mathrm{~min}$ of reaction, respectively, for PMN obtained at $24 \mathrm{~h}$ and at 15 days of infection. On the other hand, catalase had no effect on $\mathrm{Pb}$-stimulated PMN from both strains recovered after $24 \mathrm{~h}$ (Figs. 5A and 6A). The main difference between strains was observed in cells obtained after 15 days of infection, using $\mathrm{Pb}$ as stimulus. Catalase had no effect on B10.A cells, whereas it continuously decreased the CL of $\mathrm{A} / \mathrm{J}$ mouse PMN by $65 \%$ at $5 \mathrm{~min}$ to $85 \%$ at $50 \mathrm{~min}$ (Fig. 5B).

\section{Lucigenin-enhanced CL}

Figure $7 \mathrm{~A}$ shows the lucigenin-enhanced $\mathrm{CL}$ developed by $\mathrm{A} / \mathrm{J}$ and B10.A neutrophils, obtained $24 \mathrm{~h}$ after infection, with both stimuli. The curves of PMA-stimulated PMN were essentially the same for $A / J$ or $B 10 . A$ cells at both infection times (Fig. 7, A and B). At 5 min of incubation, the $\mathrm{Pb}$-stimulated $\mathrm{A} / \mathrm{J}$ cells showed higher $\mathrm{CL}$ than those of B10.A, independent of the infection time (Fig. 7, $\mathrm{A}$ and $\mathrm{B})$. At 15 days after infection, the $\mathrm{CL}$ of $\mathrm{Pb}$-stimulated PMN obtained from both mouse strains showed continuous increase with incubation time (Fig. 7B).

Lucigenin-enhanced CL, without in vitro stimulation, did not show differences between the two inbred mouse strains after $24 \mathrm{~h}$ of infection (Fig. 4C). However, a sharp decrease in B10.A cell CL was observed after 15 days of infection (Fig. 4D).

\section{P. brasiliensis killing by PMN}

Figure 8 shows the CFU counts of viable $P$. brasiliensis recovered from exudate of air pouches from $\mathrm{A} / \mathrm{J}$ and B10.A mice, at 15 days after infection, CFU of fungi cultured only in medium (100\% of growth), and CFU of co-cultives of virulent $P$. brasiliensis yeasts and PMN from both mice. The number of CFU was significantly reduced $(61 \%)$ by the interaction of virulent $P$. brasiliensis with $A / J$ mouse PMN, whereas a reduction of only $14 \%$ was caused by
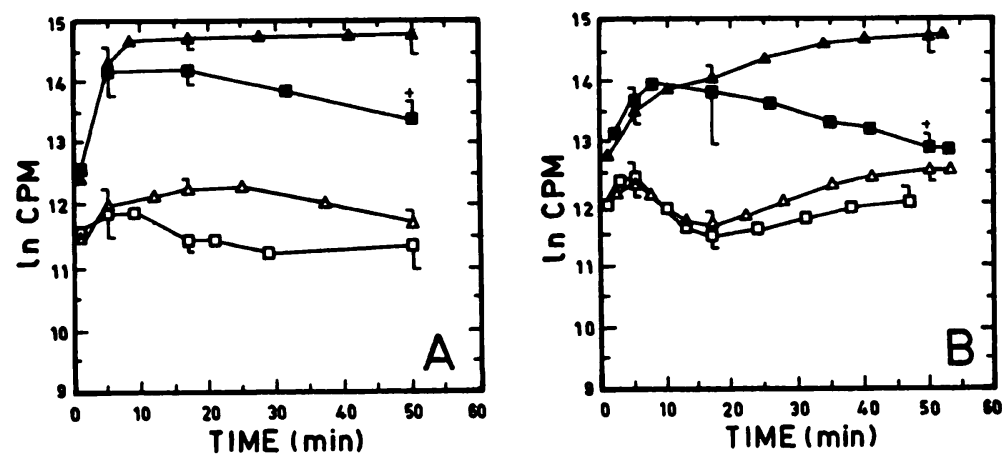

Fig. 6. Effect of catalase in the luminol-enhanced chemiluminescence of PMN from B10.A stimulated by PMA (filled symbols) or $\mathrm{Pb}$ (open symbols) $24 \mathrm{~h}(\mathrm{~A})$ or 15 days (B) after air pouch infection with $\mathrm{Pbl8} P$.brasiliensis. Without catalase $(\Delta, \Delta)$, with catalase $(\square, \square)$; ${ }^{+}$statistical difference between treatments. 

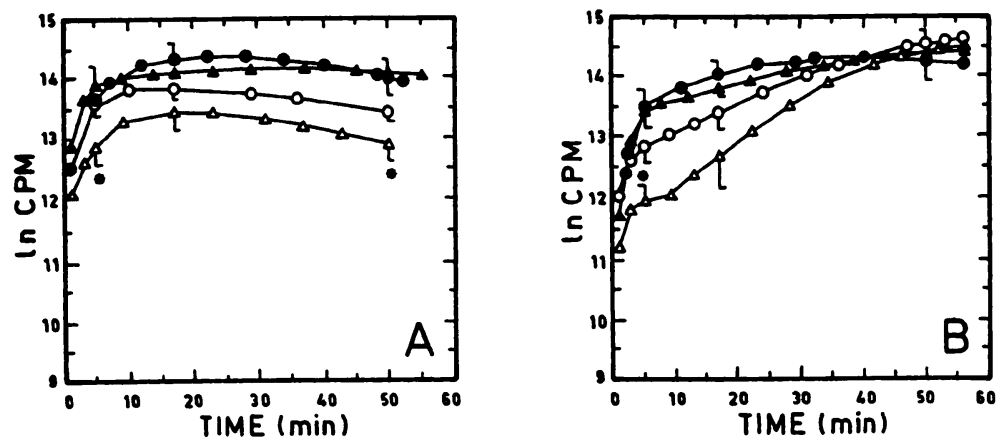

Fig. 7. Lucigenin-enhanced chemiluminescence of PMN from B10.A $(\Delta, \Delta)$ and $A / J(O, O)$, obtained $24 h(A)$ and 15 days (B) after air pouch infection (PMA, filled symbols; $\mathrm{Pb}$, open symbols). *Statistical differences between mouse strains (A/J and B10.A).

PMN from B10.A mice. It is interesting to note that 15 days after air pouch infection with $P$. brasiliensis, an expressive number of viable yeasts was recovered only from the susceptible mice.

\section{DISCUSSION}

The $\mathrm{H}_{2} \mathrm{O}_{2}$-MPO-halide system from PMN cells and from cell-free medium is an effective killing mechanism for opportunistic [18, 19] and dimorphic fungi [7, 12-16]. Air pouch inoculation in animal models provides an additional useful tool to study the interaction of PMN and $P$. brasiliensis yeast cells, since by this route a cellular population rich in neutrophils could be obtained, similar to what occurs after inoculation of lipopolysacharide [28].

In the present work, we studied the oxidative burst of PMN present in the air pouch of B10.A and A/J mice, as well as the ability of this cell population to inhibit $P$. brasiliensis growth. Two types of stimuli able to trigger $\mathrm{O}_{2}$ release by neutrophils were used: $\mathrm{PMA}$ and $\mathrm{Pb}$. The luminogenic probes, luminol and lucigenin, are commonly used to monitor PMN activation by detecting, respectively, the $\mathrm{H}_{2} \mathrm{O}_{2}-\mathrm{MPO}$ system and $\mathrm{O}_{2}^{-}[20-22,33]$.

The results herein obtained show that, during infection, the PMN present in the air pouch of $\mathrm{A} / \mathrm{J}$ mice become progressively more activated when stimulated in vitro with killed $P$. brasiliensis yeast cells. This stimulation can easily be observed by the increase of the luminol-enhanced CL of cells obtained 15 days after infection when compared with those recovered after $24 \mathrm{~h}$. This activation in the course of infection was not observed with the B10.A mice, constituting the main difference in respect to PMN behavior between the B10.A and $\mathrm{A} / \mathrm{J}$ mice.

The effects observed by the addition of catalase upon the luminol-enhanced CL clearly showed that the production of ROS depends on the stimulus utilized. When the soluble stimulus PMA was used, at any time of infection, the effect of catalase clearly showed an increasing $\mathrm{H}_{2} \mathrm{O}_{2}$ production along with the oxidative burst. However, when $\mathrm{Pb}$ was used as stimulus, PMN isolated $24 \mathrm{~h}$ after the infection were not able to release an expressive amount of $\mathrm{H}_{2} \mathrm{O}_{2}$ in the medium, since catalase had no effect in this experimental group. After 15 days of infection, only the PMN of A/J mice were able to show an early response with release of large amounts of $\mathrm{H}_{2} \mathrm{O}_{2}$.
In vitro stimulation of $P M N$ from $A / J$ mice with $\mathrm{Pb}$ showed that this cell population produces more $\mathrm{O}_{2}^{-}$than that obtained from B10.A mice. In this strain the $\mathrm{H}_{2} \mathrm{O}_{2}$ MPO-halide system is inefficient, as evidenced by depressed luminol-enhanced CL. It is noteworthy that a decrease in the spontaneous lucigenin CL after 15 days of infection occurred only with BIO.A cells. This indicates that, during the infection, the PMN from this mouse strain lose their ability to produce $\mathrm{O}_{2}$. The differences in the formation of reactive oxygen species were evidenced only when $\mathrm{PMN}$ from $\mathrm{B} 10$.A were activated in vitro with $\mathrm{Pb}$ and not when PMA was employed. A more pronounced activation of PMN from A/J mice than of PMN from B10.A mice was also obtained when zymozan particles were employed for the in vitro activation of PMN obtained from mice 15 days after s.c. infection (data not shown). Moreover, no differences in the phagocytic activity of these cells could be detected; both PMN obtained from resistant and susceptible mice were able to engulf opsonized zymozan particles (data not shown).

Macrophages are noted for their paucity in MPO (reviewed in refs. 33-35) and for their inefficiency to kill $P$. brasiliensis yeasts, allowing their intracellular multiplication [36]. However, when macrophages are activated in vitro by interferon- $\gamma$ these cells are able to kill $P$. brasil-

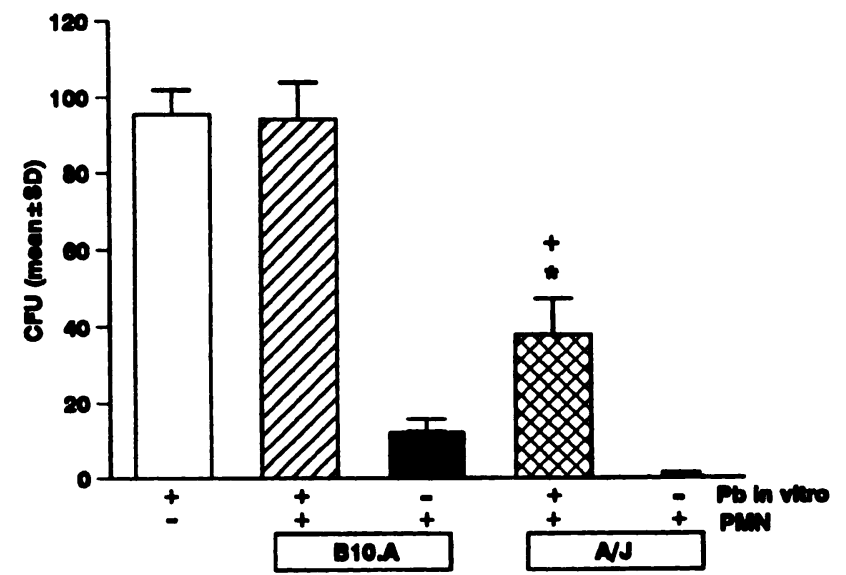

Fig. 8. Effect of co-cultivation of PMN from 8.c. air pouch of B10.A and $\mathrm{A} / \mathrm{J}$ mice with yeast cells of the virulent $\mathrm{Pb} 18 \mathrm{P}$. brasiliensis isolates in a 50:1 proportion, expressed as mean $\pm \mathrm{SE}$ of CFU counts. Controls consisted of similarly obtained PMN, without exposition to $P$.brasiliensis and of $P$. brasiliensis suspensions. *Statistical difference between the mouse strains (A/J and B10.A); ${ }^{+}$statistitical difference in relation to $P$. brasiliensis suspension. 
iensis by a mechanism independent of ROS production [37]. Our precaution in eliminating the adherent cell population in the killing experiments allows us to attribute the fungicidal role to PMN. Although 10-20\% of the cells in the exudate are mononuclear, our data clearly show that PMN from resistant mice are the most important source of ROS in the air pouch lesion of $A / J$ mice.

In parallel with these alterations, the susceptible mice were unable to markedly inhibit viable $P$. brasiliensis yeast growth, after in vitro co-cultivation with their PMN. This data, which shows a fundamental role of PMN in the control of paracoccidioidomycosis, corroborate previously obtained ones, employing athymic and euthymic mice of susceptible BALB/c background, which showed that during the first week of infection, when PMNs were abundant in the lesions, $P$. brasiliensis dissemination was under control and there was presence of fungal debris near these phagocytic cells [23].

The participation of PMN in resistance to $P$. brasiliensis infection may well extend to further stages of the evolution of the disease. In fact, the role of PMN in the immune phase of the response against some infectious agents has recently been demonstrated, as it was shown that BALB/c mice were unable to express $T$ cell-mediated immunity to Listeria monocytogenes in the absence of granulocytes [38]. Moreover, a recent study [39] described that stimulated human PMN produced interleukin-12, which may play an important role at the site of infection, inducing $T$ and natural killer cells to produce interferon- $\gamma$, the classical macrophage activator.

In our system, the PMN present in the air pouch can be subject to the effect of various cytokines produced by different cells such as the keratinocytes, mast cells, $T$ lymphocytes, macrophages, natural killer, and PMN (reviewed in refs. 37-44). These cells can produce cytokines such as interleukin-1, interleukin-3, granulocyte colony-stimulating factor, granulocyte-macrophage colony-stimulating factor, tumor necrosis factor- $\alpha$, and interferon- $\gamma$, which activate the oxidative burst and the fungicidal activity of PMN $[18,19,44]$. It is possible that the differences appointed in the present study reflect the qualitative or quantitative differences in the stimulatory cytokines present in the air pouches of the two mouse strains studied.

In contrast to the i.p. route, the s.c. route of $P$. brasiliensis inoculation leads to adequate delayed-type hypersensitivity responses and survival of both $\mathrm{A} / \mathrm{J}$ and $\mathrm{B} 10 . \mathrm{A}$ mice [2]. At 15 days of air pouch infection, both mouse strains showed intense delayed-type hypersensitivity (data not shown). Therefore, the PMN of these mice can be subject to the effects of various cytokines, which can activate or down-regulate the oxidative burst and the fungicidal activity of these cells.

PMN are now accepted as participating not only in the initial, natural immune response, but also in the subsequent immune phase of anti-infectious resistance. Seen under this light, our present results suggest that PMN of the resistant mice, being more activated and also able to better control $P$. brasiliensis growth than those of the sus- ceptible ones, can, at the initial stages of infection, effectively diminish the fungal load. During later stages, the PMN of the resistant mice may be more effective in promoting and/or participating in cell interactions that result, ultimately, in the establishment of protective immunity. In conclusion, the high amount of activated PMN in vivo in air pouch and ROS production by PMN from $A / J$ cells points to a central role of these cells in the fast resolution of $P$. brasiliensis infection. Moreover, the $\mathrm{H}_{2} \mathrm{O}_{2}$-MPO-halide system appears to be an important source of oxidant species contributing to $P$. brasiliensis killing and confirm ealier data that shows that deficiency in MPO leads to increased susceptibility to fungal infections.

\section{ACKNOWLEDGMENTS}

The authors are grateful to Celina Arruda for technical assistance and helpful suggestions, to Cristine A. Colella for help with the illustrations, and to Rosana D. Prisco for the statistical analysis.

This work was supported by Fundação de Amparo a Pesquisa grants 91/0497-1 and 92/4405-7.

\section{REFERENCES}

1. Restrepo, A. (1988) Immune response to Paracoccidioides brasiliensis in human and animal hosts. In Current Topics in Medical Mycology. (M.R. Mc Ginnis, ed.), vol. 2, Springer-Verlag, New York, 239-275.

2. Calich, V.L.G., Singer-Vermes, L.M., Russo, M., Vaz, C.A.C., Burger, E. (1993) Immunogenetics in paracoccidioidomycosis. In: Paracoccidioidomycosis. (M.F. Franco, C.S. Lacaz, A. Restrepo-Moreno, G. Del Negro, eds.) CRC Press, Miami, 151-168.

3. Calich, V.L.C., Kipnis, T.L., Mariano, M., Fava Neto, C., Dias da Silva, W. (1979) The activation of the complement system by Paracoccidioides brasiliensis in vitro: its opsonic effect and possible significance for an in vivo model of infection. Clin. Immun. Immunopathol. 12, $20-30$.

4. Calich, V.L.G., Vaz, C.A.C., Burger, E. (1985) PMN chemotactic factor produced by glass adherent cells in the acute inflammation caused by Paracoccidioides brasiliensis. Br. J. Exp. Pathol. 66, 57-65.

5. Brummer, E., Castaneda, E., Restrepo, A. (1993) Paracoccidioidomycosis: an update. Clin. Microb. Rev. 6, 39-117.

6. Restrepo, A., Velez, H. (1975) Efectos de la fagocitosis in vitro sobre Paracoccidioides brasiliensis. Sabouraudia 13, 10-21.

7. McEwen, J.G., Brummer, E., Stevens, D.A., Restrepo, A. (1987) Effect of murine polymorphonuclear leukocytes on the yeast form of $P$. brasiliensis $A m$. J. Trop. Med. Hyg. 36, 603-608.

8. Brummer, E., McEwen, F.G., Stevens, D.A. (1986) Fungicidal activity of murine inflammatory polymorphonuclear neutrophils, comparison with murine peripheral blood PMN. Clin. Exp. Immun. 66, 681-690.

9. Brummer, E., Sugar, A.M., Stevens, D.A. (1984) Immunological activation of polymorphonuclear neutrophils for fungal killing: studies with murine cells and Blastomyces dermatitidis in vitro. J. Leukoc. Biol. 36, 505-520.

10. Goihman-Yahr, M., Essenfeld-Yahr, E., Albornoz, M.C. (1980) Defect of in vitro digestive ability of polymorphonuclear leukocytes in paracoccidiodomycosis. Infect. Immun. 28, 557-566.

11. Schaffner, A., Davis, C.E., Schaffner, T., Markert, M. (1986) In vitro susceptibility of fungi to killing by neutrophil granulocytes discriminates between primary pathogenicity and opportunisms. J. Clin. Invest. 78, 511-524.

12. McEwen, J.G., Sugar, A.M., Brummer, E., Restrepo, A., Stevens, D.A. (1984) Toxic effect of products of oxidative metabolism on the yeast form of $\boldsymbol{P}$. brasiliensis J. Med. Microb. 18, 423-428.

13. Sugar, A.M., Chahal, R.S., Brummer, E., Stevens, D.A. (1983) Susceptibility of Blastomyces dermatitidis strains to products of oxidative metabolism. Infect. Immun. 41, 908-912.

14. Brummer, E., Sugar, A.M., Stevens, D.A. (1985) Enhanced oxidative burst in immunologically activated but not elicited polymorphonuclear leukocytes correlates with fungicidal activity. Infect. Immun. 49, 396-441.

15. Brummer, E., Kurita, N., Yoshida, S., Nishimura, K., Miyaji, M. (1992) A basis for resistance of Blastomyces dermatitidis killing by human neutrophils: inefficient generation of myeloperoxidase system products. J. Med. Vet. Mycol. 30, 233-243. 
16. Kurita, N., Terao, K., Brummer, E., Ito, E., Nishimura, K., Miyaji, M. (1991) Resistance of Histoplasma capsulatum to killing by human neutrophils, evasion of oxidative burst and lysosoma fusion products. Mycopathologia 115, 207-213.

17. Wagner, D.K., Collins-Lech, C., Sohnle, P.G. (1986) Inhibition of neutrophil killing of Candida albicans pseudohyphae by substances which quench hypochlorous acid and chloramines. Infect. Immun. 51, 731-735.

18. Diamond, R.D., Lyman, C.A., Wysong, D.R. (1991) Disparate effects of interferon-gama and tumor necrosis factor-alpha on early neutrophil respiratory burst and fungicidal responses to Candida albicans hyphae in vitro. J. Clin. Invest. 87, 711-720.

19. Kowanko, I.C., Ferrante, A., Harvey, D.P., Carman, K.L. (1991) Granulocyte-macrophage colony-stimulating factor augments neutrophil killing of Torulopsis glabrata and stimulates neutrophil respiratory burst and degranulation. Clin. Exp. Immun. 83, 225-230.

20. Allen, R.C., Loose, L.D. (1976) Phagocytic activation of luminol dependent chemiluminescence in rabbit alveolar and peritoneal macrophages. Biochem. Biophys. Res. Commun. 69, 245-252.

21. Faulkner, K., Fridovich, I. (1993) Luminol and lucigenin as detectors for $0_{2}{ }^{-}$. Free Rad. Biol. Med. 15, 447-451.

22. Mikenberg, I., Ferber, E. (1984) Lucigenin dependent chemiluminescence as a new assay for NADPH oxidase activity in particulate fractions of human polymorphonuclear leukocytes. J. Immun. Meth. 71, 61-67.

23. Lenzi, H.L., Calich, V.L.G., Miyaji, M., Sano, A., Nishimura, K., Burger, E. (1994) Fibrosis patterns of lesions developed by athymic and euthymic mice infected with Paracoccidioides brasiliensis. Braz. J. Med. Biol. Res. 27, 2301-2308.

24. Kashino, S.S., Singer-Vermes, L.M., Calich, V.L.G., Burger, E. (1990) Alterations in the pathogenicity of one Paracoccidioides brasiliensis isolate do not correlate with its in vitro growth. Mycopathologia, 111, 173-180.

25. Fava Netto, C. (1961) Contribuição para o estudo imunológico da blastomicose de Lutz. Rev. Inst. Adolfo Lutz 21, 99-194.

26. Kashino, S.S., Calich, V.L.G., Singer-Vermes, L.M., Abrahamsohn, P.A. Burger, E. (1987) Growth curves, morphology and ultrastructure of ten Paracoccidioides brasiliensis isolates. Mycopathologia 99, 119-128.

27. Berliner, M.D., Reca, M.E. (1966) Vital staining of Histoplasma capsulatum with Janus Green B. Sabouraudia 5, 26-29.

28. Harmsen, A.G., Havell, E.A. (1990) Roles of tumor necrosis factor and macrophages in lipopolysacaharide-induced accumulation of neutrophils in cutaneous air pouches. Infect. Immun. 52, 297-302.

29. Carson, F.L., Martin, J.H., Lynn, J.A. (1973) Formalin fixation for election microscopy. A re-evaluation. Am. J.Clin. Pathol. 59, 365-373.
30. Castañeda, E. Brummer, E. Perlman, A.M., McEwen, J.C Stevens, D.A. (1988) A culture medium for Paracoccidioides brasiliensis with high plating efficiency, and the effect of siderophores. J. Med. Vet. Mycol. 26, 351-358.

31. Singer-Vermes, L.M., Ciavaglia, M.C., Kashino, S.S., Burger, E., Calich, V.L.G. (1992) The source of the growth-promoting factor(s) affects the plating efficiency of $P$. brasiliensis. J. Med. Vet. Mycol. 30, 261-264.

32. Zar, J.H. (1984) Biostatistical Analysis, 2nd ed., Prentice-Hall, NJ.

33. Brestel, E.P. (1987) Mechanisms of cellular chemiluminescence. In Cellular Chemiluminescence, vol. 1, chapt. 9, 93-103.

34. Peterson, P.K., Gaziano, E., Suh, H.J., Devalon, M., Petersen, L., Krane, W.F. (1985) Antimicrobial activities of dialysate-elicited and resident human peritoneal macrophages. Infect. Immun. 49, 212-218.

35. Rosen, G.M., Pou, S., Ramos, C.L., Cohen, M.S., Britigan, B.E. (1995) Free radicals and phagocytic cells. FASEB J. 9, 200-209.

36. Brummer, E., Hanson, L.H., Restrepo, A., Stevens, D.A. (1989) Intracellular multiplication of $P$. brasiliensis in macrophage killing and restriction of multiplication by activated macrophages. Infect. Immun. 57, 2289-2294.

37. Brummer, E., Hanson, L.H., Stevens, D.A. (1988) Gamma interferon activation of macrophages for killing of Paracoccidioides brasiliensis and evidence for nonoxidative mechanisms. Int. J. Immunopharmacol 10, 945-952.

38. Appelberg, R., Castro, A.G., Silva, M.T. (1994) Neutrophils as affector cells of T-cell-mediated, acquired immunity in murine listeriosis. Immunology 83, 302-307.

39. Cassatella, M.A., Meda, L., Gasperini, S., D'Andrea, A., Ma, X., Trinchieri, G. (1995) Interleukin-12 production by human polymorphonuclear leukocytes. Eur. J. Immun. 25, 1-5.

40. Bos, J.D., Kapsenberg, M.L. (1993) The skin immune system: progress in cutaneous biology. Immun. Today 14, 75-78.

41. Ribeiro, R.A., Flores, L.A., Cunha, F.Q., Ferreira, S.H. (1991) IL-8 causes in vivo neutrophil migration by a cell dependent mechanism. Immunology 73, 472-477.

42. Djeu, J.Y. (1992) Cytokines and anti-fungal immunity. Adv. Exp. Med. Biol. 319, 217-223.

43. Lloyd, A.R., Oppenheim, J.J. (1992) Poly's lament: the neglected role of the polymorphonuclear neutrophil in the afferent limb of the immune response. Immun. Today 13, 169-172.

44. Sullivan, G.W., Carper, H.T., Mandell, G.L. (1993) The effect of three human recombinant hematopoietic growth factors (granulocyte-macrophage colonystimulating factor, granulocyte colony-stimulating factor and interleukin-3) on phagocyte oxidative activity. Blood 81, 1863-1970. 